\title{
Survival Predictors of Preterm Neonates - Single Center Experience
}

\author{
Selma Dizdar ${ }^{*}$, Verica Mišanović ${ }^{1}$, Refet Gojak $^{2}$, Sabina Terzić ${ }^{1}$, Duško Anić1, Hajrija Maksić1, \\ Elmedina Mrkulić ${ }^{1}$, Zijo Begić ${ }^{1}$, Basri Lenjani ${ }^{3}$, Kenan Ljuhar ${ }^{4}$.
}

Received: 06 June 2021 / Accepted: 02 July 2021 / Published online: 20 July 2021

This article is published with open access at https://journal.astes.org.al

(C) The author(s) 2021. \& Copyright (C) 2021, the Albanian Society for Trauma and Emergency Surgery

(c) The Albanian Journal of Trauma and Emergency Surgery is an Open Access Journal. All articles are distributed under the terms of the Creative Commons Attribution Non-Commercial License: http://creativecommons.org/licenses/by-nc/4.0/) which permits unrestricted non-commercial use, distribution, and reproduction in any medium provided the original work is properly cited.

\section{Abstract}

Introduction: Adequate prenatal and postnatal care for preterm neonates not only affects the survival rate, but also the occurrence of chronic diseases, and in the future also affects the quality of life of that children.

Aim: To examine the influence of independent predictors (weeks of gestation, body weight, sex) on the outcome of the disease and to analyze the influence of the applied ventilatory mode on the final outcome of treatment.

Material and methods: The study included neonates $(n=248)$ born prematurely who were treated in the neonatal intensive care unit for a period of one year due to immaturity-related difficulties.

Results: The mean age of male neonates $(\mathrm{n}=119)$ at birth was $31.13 \pm 3.3$ weeks of gestation $(\mathrm{WG})$, and females $(\mathrm{n}=129) 31.59 \pm 3.2$ WG. Weeks of gestation have a statistically significant effect on survival $(p=0.0001)$, for each more week of gestation, the chances of survival increase by $21 \%$. There was no significant difference between birth weight and sex $(p=0.289)$, and the birth weight of the neonates had a statistically significant effect on survival $(p=0.0001)$. For every 10 grams of body weight, in our sample, the chance of survival increases by $2 \%$. Ventilation mode showed a statistically significant effect on neonatal survival $(\mathrm{p}<0.05)$, and intubation mode was used as an indicator. If neonates are switched from non-invasive to invasive ventilation mode, the chance of survival in our sample is reduced by $88 \%$.
\end{abstract}

Conclusion: Weeks of gestation, birth weight, and the use of a noninvasive mode of ventilation are predictors of a positive outcome for preterm neonates.

Keywords. Preterm Birth, Neonatal, Intensive Care, born prematurely

\section{Introduction}

Prematurity is defined as the birth of a child before the 37 th week of gestation (WG). The classification of preterm neonates can be performed in relation to the weeks of

Original article, no submission or publication in advance or in parallel

\section{* Corresponding author:}

Selma Dizdar MD

凶selma1.dizdar@gmail.com

1 Pediatric Clinic, Clinical Center University of Sarajevo, Sarajevo, BOSNIA and HERZEGOVINA

2 Clinic for Infectious diseases, Clinical Center University of Sarajevo, BOSNIA and HERZEGOVINA

3 Emergency Clinic, University Clinical Centre of Kosovo, Pristina, KOSOVO

4 Emergency Medical Center of Canton Sarajevo, BOSNIA and HERZEGOVINA pregnancy and birth weight [1]. Worldwide, the incidence of preterm birth is different and is influenced by different factors. About 15 million children are born prematurely worldwide during the year. In developed European countries, the incidence is about 5\%, while in African countries this incidence is $18 \% .84 \%$ of births occur in the period from 32 to $36 \mathrm{WG}, 10 \%$ of births in the period from 28 to 32 $\mathrm{WG}$, and $5 \%$ before $28 \mathrm{WG}$. According to datas from 2014 in the United States, about $9.57 \%$ of children are born prematurely. While in 2015, 8.1\% of children had a lower birth weight [2.3]. Neonatal death is defined as the death of a newborn before the 28th day of life. The definition of the preterm birth rate used is "all livebirths before 37 completed weeks, whether singleton, twin, or higher order multiples, divided by all livebirths in the population". [4]. Preterm birth rate is a direct indicator of, among other things, the quality of prenatal and postnatal medical care. There are several factors that impact on the survival rate of preterm neonates, such as: weeks of gestation (WG) at 
birth, associated congenital anomalies, the social status of the mother and the level of neonatal care. Prenatal use of steroids to prevent respiratory distress, as well as early surfactant administration, noninvasive ventilation, and other supportive therapies used in neonatal intensive care units have a significant impact on increasing the survival rate of preterm neonates $[5,6,7]$. Adequate prenatal and postnatal care for preterm neonates not only affects the survival rate, but also the occurrence of chronic diseases, and in the future also affects the quality of life of that children. Aim of this paper was to examine the influence of independent predictors (weeks of gestation, body weight, sex) on the outcome of the disease and to analyze the influence of the applied ventilatory mode on the final outcome of treatment.

\section{Patients and Methods}

Patients and study design; During the one-year period (January 1, 2019 to December 31, 2019), 402 neonates were hospitalized at the Department of Neonatal Intensive Care of the Pediatric Clinic Clinical Center University in Sarajevo. Out of the total number, 248 neonates were admitted to the Department due to preterm birth and difficulties caused by fetal immaturity. All preterm neonates with respiratory problems caused by immaturity were included in the study. We excluded from the study preterm neonates with associated congenital anomalies and other difficulties not related to the respiratory system.

Methods; The study is prospective, and analyzed the influence of gender, weeks of gestation at birth, body weight, surfactant application, ventilatory mode, and duration of ventilatory support on the disease outcome itself. Informed consent was obtained from all parents following an explanation of the purpose of the study. Ethical approval was obtained from Ethical Committee of Clinical Center University of Sarajevo.

Statistical analysis; The results of statistical analyzes are presented in absolute (n) and real values (\%), arithmetic mean and standard deviation, and comparisons between them with the appropriate test (t-test). The independent influence of individual factors on the binary dependent variable change (survived / did not survive), in a function of time, was compared with the help of univariate and multivariate Cox regression analysis. The analysis data are presented in a table. Statistical level of $95 \%(p<0.05)$ was taken as significant for all performed tests.

\section{Results}

Out of the total number, $129(52.0 \%)$ subjects were female and $119(48.0 \%)$ male. The mean age of male neonates at birth was $31.13 \pm 3.3 \mathrm{WG}$, and females $31.59 \pm 3.2 \mathrm{WG}$, with no significant statistical difference between weeks of gestation at birth and sex $(p=0.259)$. Weeks of gestation have a statistically significant effect on survival in our study $(p=0.0001)$. In our study, for each more week of gestation, the chances of survival increase by $21 \%$, while in the population of such subjects the chance ranges between $29-12 \%$. The average birth weight of male neonates was $1791.6 \pm 630.6$ grams and females $1709.8 \pm 580.6$ grams, in our study we found that there was no significant statistical differences between birth weight and sex $(p=0.289)$. The birth weight of the neonates has a statistically significant effect on survival $(p=0.0001)$. (Tab. 1)

For every 10 grams of birth weight, in our study, the chance of survival increases by $2 \%$, while in the population the chance of survival increases by $3-1 \%$. We administered the surfactant in 117 (47.2\%) cases, while 131 (52.8\%) did not receive the surfactant. The reason for not administrating surfactant in 131 subjects or $52.8 \%$ of cases was the higher gestational age of the neonates, good general condition - during initial care, satisfactory radiological findings of the respiratory system as well as a good response to initial treatment and care. Out of the 117 neonates, 87 (74.3\%) received a single dose of surfactant. Univariate Cox regression analysis examined the influence of independent predictors in a function of time on the dependent variable, disease outcome (survived / did not survive). In our study,

Table 1. Individual influence of independent predictors in a function of time on the dependent variable, disease outcome (survived / did not survive)

\begin{tabular}{|l|c|c|c|c|c|c|c|c|}
\hline & $B$ & SE & Wald & $d f$ & $p$. & \multicolumn{2}{c|}{$\operatorname{Exp}(\boldsymbol{B})$} & \multicolumn{2}{c|}{ 95,0\% CIfor Exp(B) } \\
\hline & & & & & & & Lower & Upper \\
\hline Sex (m/f) &, 029 &, 309 &, 009 & 1 & 0,924 & 1,030 &, 562 & 1,885 \\
\hline Weeks of gestation &,- 235 &, 055 & 18,055 & 1 &, 0001 &, 790 &, 709 &, 881 \\
\hline Birth weight (x10 grams) &,- 021 &, 004 & 21,784 & 1 &, 0001 &, 980 &, 971 &, 988 \\
\hline Received surfactant (yes/mo) &, 675 &, 462 & 2,130 & 1 & 0,144 & 1,964 &, 793 & 4,860 \\
\hline Surfactant dose (0/1/2/3) &, 296 &, 163 & 3,306 & 1 & 0,066 & 1,347 &, 980 & 1,851 \\
\hline MV modus & & & 19,008 & 2 &, 000 & & & \\
\hline MV modus(1) Nasal CPAP & 11,020 & 125,830 &, 008 & 1 &, 930 & 61053,434 &, 000 & $7,809 \mathrm{E}+111$ \\
\hline MV modus(2)Invasive ventilation & $-2,120$ &, 486 & 19,000 & 1 &, 0001 &, 120 &, 046 &, 311 \\
\hline
\end{tabular}

$B$ - standardized regression coefficient, Wald - nonstandardized regression coefficient, df - degrees of freedom, $p$ - significance of the statistical test, 
Table 2. Common influence of independent predictors in a function of time on the dependent variable, disease outcome (survived / did not survive).

\begin{tabular}{|l|c|c|c|c|c|c|c|c|}
\hline Model 1 & $\boldsymbol{B}$ & SE & Wald & $d f$ & Sig. & \multicolumn{2}{|c|}{ Exp(B) } & \multicolumn{2}{|c|}{$95,0 \%$ CIfor Exp(B) } \\
\hline & & & & & & & Lower & $U_{\text {pper }}$ \\
\hline Weeks of gestation &, 078 &, 090 &, 759 & 1 &, 384 & 1,081 &, 907 & 1,290 \\
\hline Birth wight (x10 grams) &,- 021 &, 007 & 9,678 & 1 &, 002 &, 979 &, 966 &, 992 \\
\hline MV modus $^{\text {MV modus }}{ }^{(1)}$ & & & 12,508 & 2 &, 002 & & & \\
\hline MV modus $^{(2)}$ & 12,111 & 124,003 &, 010 & 1 &, 922 & 181831,70 &, 000 & $6,47 \mathrm{E}+11$ \\
\hline
\end{tabular}

$B$ - standardized regression coefficient, Wald - nonstandardized regression coefficient, $d f$ - degrees of freedom,

p - significance of the statistical test, $\operatorname{EXP}(B)$ - odds ratio with $95 \%$ confidence interval (CI) (lower, upper)

the sex of the subjects, as well as the administration of surfactant (compared to non-administration of the same) did not show a statistically significant effect on survival ( $p$ $>0.05$ ). Multivariate Cox regression analysis examined the influence of independent predictors (weeks of gestation, birth weight and mode of ventilation) in a function of time on the dependent variable, disease outcome (survived / did not survive). Lower weeks of gestation as well as lower values of birth weight statistically significant affect the survival rate. Ventilation mode also showed a univariate statistically significant effect on neonatal survival $\mathrm{p}<0.05$, and intubation mode was used as an indicator. If neonates are transfered from the mode of non-invasive to the mode of invasive ventilation, the chance of survival in our study is reduced by $88 \%$, while in the newborn population it ranges between $95-69 \%$. (tab. 2)

\section{Discussion}

According to the World Health Organisation (WHO), globally, the number of preterm births is $11 \%$. This percentage varies in the range of 5\% in European countries and $18 \%$ in some parts of Africa [2, 3]. In the United States, approximately 550,000 preterm neonates are born annually [2, 3]. The rate of preterm birth in Bosnia and Herzegovina in 2012 was $7.9 \%$ according to the data stated in the EMBARGO study - WHO [11]. In our study in the period January 1, 2019 to December 31, 2019, a total of 3,213 neonates were born at the Clinic for Gynecology and Obstetrics. In the same period, a total of 402 neonates were admitted to the Department of Neonatal Intensive Care, and of the total number, $248(61.6 \%)$ were admitted due to preterm birth and difficulties caused by immaturity.

According to Blencowe $H$ et al. of the total number of preterm births, $84 \%$ occurs in the period of 32-36 weeks of gestation (WG), $10 \%$ in the period of $28-32 \mathrm{WG}$ and $5 \%$ at the age of less than 28 WG. [4]. In our study, there was no statistically significant difference between the sex of preterm neonates treated at the Department of Neonatal Intensive Care, nor were there differences in their birth weight $[9,10$, $12,13,14,15]$. It should be noted that neonates born as late prematures and who were in good general condition were not hospitalized at the Department of Neonatal Intensive Care. As Watkins WJ et al. states the mortality rate of preterm neonates correlates with birth weight and weeks of gestation [10].

In our study, we concluded that for each week of gestation more, the chances of survival increase by $21 \%$. The results obtained coincide with data from 2017 which state that the mortality rate in the United States per 1000 live births increases with lower gestational age [8]. The birth weight of the neonates has a statistically significant effect on survival. [15, 16, 17, 18, 19, 20, 21]. In our study, for every 10 grams of body weight of the neonate, the chance of survival increased by $2 \%$, while in the population this chance ranges between 3-1\%. Advances in the approach to the treatment of preterm neonates in intensive care units, which include, among other things, early use of surfactant, non-invasive ventilation and other supportive therapy, have resulted in a reduced neonate mortality rate.

The situation in Bosnia and Herzegovina has changed significantly with the establishment of neonatal intensive care. In 1986, the infant mortality rate was 26.1 per 1,000 live births, and in 2019, 5.1 per 1,000 live births (World BankWorld Development indicators) [11]. In a large prospective study, Patel RM et al. and Norman $M$ et al. have shown that adequate access and initially adequate care of preterm neonates significantly increases the survival rate of preterm neonates $[12,13]$. In our study, due to clinical and radiological signs of respiratory distress syndrome (RDS), surfactant was administered to $117(47.2 \%)$ preterm neonates, while due to good general condition and good response to initial care, 131 of them did not receive surfactant. In the presented model, the greatest influence on survival had the ventilation mode, then the birth weight and at the end the weeks of gestation. In our study, if preterm neonate for any reason was translated from non-invasive to invasive ventilatory mode, the chance of survival was reduced by $88 \%$, while in the population this value ranges between $95-69 \%$. Although there are studies that state that male preterm neonates have a higher mortality rate than females $[15,16]$, in our study, the sex of the subjects did not show a statistically significant impact on survival. Simultaneously, initial adequate care involving early surfactant administration as well as 
noninvasive ventilation showed a better outcome compared to repeated surfactant doses that did not prove statistically significant for the survival of treated subjects. The study limits are a short study period (12 months), lack of data on the obstetric measures (prenatal use of corticosteroids), as well as insight into other factors that contribute to mortality such as infections, bleeding, necrotic enterocolitis of the neonates.

\section{Conclusion}

Weeks of gestation, birth weight, and the use of a noninvasive mode of ventilation are predictors of a positive outcome for preterm neonates. Each week of pregnancy increases the chance of survival by one-fifth, which can be an important indicator for gynecologists to try to influence on the duration of pregnancy as much as possible (in the case of pathological and risky pregnancies). The result of prolonged gestation is a higher birth weight and a higher chance of survival ( $2 \%$ for each 10 grams of body weight)

Author's Contribution: Each author gave substantial contribution to the conception or design of the work and in the acquisition, analysis and interpretation of data for the work. Each author had role in drafting the work and revising it critically for important intellectual content. Each author gave final approval of the version to be published and they agree to be accountable for all aspects of the work in ensuring that questions related to the accuracy or integrity of any part of the work are appropriately investigated and resolved.

\section{Financial support and sponsorship: Nil.}

Conflicts of interest: There are no conflicts of interest.

\section{References:}

1. Kelly MM. The basics of prematurity. J Pediatr Health Care. 2006 Jul-Aug;20(4):238-44. doi: 10.1016/j. pedhc.2006.01.001.

2. Harrison MS, Goldenberg RL. Global burden of prematurity. Semin Fetal Neonatal Med. 2016 Apr;21(2):74-9. doi: 10.1016/j.siny.2015.12.007.

3. Glass HC, Costarino AT, Stayer SA, Brett CM, Cladis F, Davis PJ. Outcomes for extremely premature infants. Anesth Analg. 2015;120(6):1337-1351. doi:10.1213/ ANE.0000000000000705

4. Blencowe H, Cousens S, Oestergaard MZ, Chou D, Moller AB, Narwal R, Adler A, Vera Garcia C, Rohde S, Say L, Lawn JE. National, regional, and worldwide estimates of preterm birth rates in the year 2010 with time trends since 1990 for selected countries: a systematic analysis and implications. Lancet. 2012 Jun 9;379(9832):2162-72. doi: 10.1016/S01406736(12)60820-4.

5. Field DJ, Dorling JS, Manktelow BN, Draper ES. Survival of extremely premature babies in a geographically defined population: prospective cohort study of 1994-9 compared with 2000-5. BMJ. 2008 May 31;336(7655):1221-3. doi: 10.1136/bmj.39555.670718.BE.
6. Fanaroff AA, Stoll BJ, Wright LL, Carlo WA, Ehrenkranz RA, Stark AR, Bauer CR, Donovan EF, Korones SB, Laptook AR, Lemons JA, Oh W, Papile LA, Shankaran S, Stevenson DK, Tyson JE, Poole WK; NICHD Neonatal Research Network. Trends in neonatal morbidity and mortality for very low birthweight infants. Am J Obstet Gynecol. 2007 Feb;196(2):147.e1-8. doi: 10.1016/j.ajog.2006.09.014.

7. Zeitlin J, Ancel PY, Delmas D, Bréart G, Papiernik E; EPIPAGE and MOSAIC Ile-de-France Groups. Changes in care and outcome of very preterm babies in the Parisian region between 1998 and 2003. Arch Dis Child Fetal Neonatal Ed. 2010 May;95(3):F188-93. doi: 10.1136/adc.2008.156745.

8. Goldenberg RL, Culhane JF, Iams JD, Romero R. Epidemiology and causes of preterm birth. Lancet. 2008 Jan 5;371(9606):75-84. doi: 10.1016/S0140-6736(08)60074-4. PMID: 18177778; PMCID: PMC7134569.

9. Medjedovic E, Kurjak A. Doppler ultrasonography of the uterine artery in correlation with KANET. J Perinat Med. 2020 Dec 22:jpm-2020-0544. doi: 10.1515/jpm-2020-0544.

10. Watkis $\mathrm{Wj}$, Kotecha SJ, Kotecha S. All- Cause Mortality of Low Birthweight Infants in Infancy, Childhood, and Adolescence: Population Study of England and Wales. PloSMed 2016; 13:e1002018.

11. InfantMortality Rate for Bosnia and Herzegovina.URL: https:// alfred.stlouisfed.org/series?seid=SPDYNIMRTINBIH\&utm source=series_page\&utm_medium=related_content\&utm term $=$ related_resources\&utm_campaign $=$ alfred $\quad$ (retrieved March 10, 2021)

12. Patel RM, Kandefer S, Walsh MC, Bell EF, Carlo WA, Laptook AR, Sánchez PJ, Shankaran S, Van Meurs KP, Ball MB, Hale EC, Newman NS, Das A, Higgins RD, Stoll BJ; Eunice Kennedy Shriver National Institute of Child Health and Human Development Neonatal Research Network. Causes and timing of death in extremely premature infants from 2000 through 2011. N Engl J Med. 2015 Jan 22;372(4):331-40. doi: 10.1056/NEJMoa1403489.

13. Norman M, Hallberg B, Abrahamsson T, Björklund LJ, Domellöf M, Farooqi A, Foyn Bruun C, Gadsbøll C, Hellström-Westas L, Ingemansson F, Källén K, Ley D, Maršál K, Normann E, Serenius F, Stephansson O, Stigson L, UmBergström P, Håkansson S. Association Between Year of Birth and 1-Year Survival Among Extremely Preterm Infants in Sweden During 2004-2007 and 2014-2016. JAMA. 2019 Mar 26;321(12):1188-1199. doi: 10.1001/jama.2019.2021.

14. Zeitlin J, El Ayoubi M, Jarreau PH, Draper ES, Blondel B, Künzel W, Cuttini M, Kaminski M, Gortner L, Van Reempts P, Kollée L, Papiernik E; MOSAIC Research Group. Impact of fetal growth restriction on mortality and morbidity in a very preterm birth cohort. J Pediatr. 2010 Nov;157(5):733-9.e1. doi: 10.1016/j.jpeds.2010.05.002.

15. Kent AL, Wright IM, Abdel-Latif ME; New South Wales and Australian Capital Territory Neonatal Intensive Care Units Audit Group. Mortality and adverse neurologic outcomes are greater in preterm male infants. Pediatrics. 2012 Jan;129(1):124-31. doi: 10.1542/peds.2011-1578.

16. Garfinkle J, Yoon EW, Alvaro R, Nwaesei C, Claveau M, Lee SK, Shah PS; Canadian Neonatal Network Investigators. Trends in sex-specific differences in outcomes in extreme preterms: progress or natural barriers? Arch Dis Child Fetal Neonatal Ed. 2020 Mar;105(2):158-163. doi: 10.1136/ archdischild-2018-316399.

17. Neto RM, Ramos JGL, Medjedovic E, Begic E. Increased of 
the carotid intima media thickness in preeclampsia. J Perinat Med. 2020 Oct 25;48(8):787-791. doi: 10.1515/jpm-20200158 .

18. Oskovi Kaplan ZA, Ozgu-Erdinc AS. Prediction of Preterm Birth: Maternal Characteristics, Ultrasound Markers, and Biomarkers: An Updated Overview. J Pregnancy. 2018; 2018: 8367571. doi:10.1155/2018/8367571

19. Hughes K, Sim S, Roman A, Michalak K, Kane S, Sheehan P. Outcomes and predictive tests from a dedicated specialist clinic for women at high risk of preterm labour: A ten-year audit. Aust N Z J Obstet Gynaecol. 2017 Aug;57(4):405-411. doi: 10.1111/ajo.12610.

20. Krupa FG, Faltin D, Cecatti JG, Surita FG, Souza JP. Predictors of preterm birth. Int J Gynaecol Obstet. 2006 Jul;94(1):5-11. doi: 10.1016/j.ijgo.2006.03.022.

21. TROSHANI, A., \& VEVECKA, E. (2020). The Impact of Timing of Elective Cesarean Delivery at Term in Neonatal Respiratory Morbidity. Albanian Journal of Trauma and Emergency Surgery, 4(2), 653 - 660. https://doi. org/10.32391/ajtes.v4i2.93 